\title{
High transference number enabled by sulfated zirconia superacid for lithium metal batteries with carbonate electrolytes
}

\section{Sang-Gil Woo}

Korea Electronics Technology Institute

\section{Eun-Kyoung Hwang}

Korea Electronics Technology Institute

Hee-Kook Kang

Korea Electronics Technology Institute

Haeun Lee

Korea Electronics Technology Institute

Je-Nam Lee

Korea Electronics Technology Institute

Goojin Jeong

Korea Electronics Technology Institute

Dong-Joo Yoo

Seoul National University https://orcid.org/0000-0001-5656-8613

Jimin Lee

Seoul National University

Sungchan Kim

Seoul National University

Ji-Sang Yu

Korea Electronics Technology Institute

Jang Wook Choi ( $\sim$ jangwookchoi@snu.ac.kr)

Seoul National University https://orcid.org/0000-0001-8783-0901

\section{Article}

Keywords: Lithium Metal Batteries, Dendrites, Solid-Electrolyte-Interphase, Superacid

Posted Date: September 10th, 2020

DOI: https://doi.org/10.21203/rs.3.rs-73435/v1 
License: (c) (i) This work is licensed under a Creative Commons Attribution 4.0 International License. Read Full License

Version of Record: A version of this preprint was published at Energy \& Environmental Science on January 1st, 2021. See the published version at https://doi.org/10.1039/D0EE03967E. 


\section{Abstract}

The prospect of increasing the energy density has promoted research on lithium metal batteries. Yet, avoiding the uncontrolled growth of lithium dendrites and the resulting interfacial instability to ensure the practical viability of the given battery technology remains a considerable challenge. Here, we report coating the separator with sulfated zirconia superacid to achieve a high lithium ion transference number of 0.92 and compelling cycle life when a full-cell paired with a LiNi0.82Co0.07Mn0.1102 cathode was tested in a carbonate electrolyte under practical operating conditions. The exceptionally high transference number is attributed to strengthened binding of the PF6- anion of the lithium salt with the superacid. Furthermore, a trace amount of water bound to the superacid reacts with PF6- to induce a mechanically stable solid-electrolyte-interphase (SEI) layer rich in LixPOyFz. This study demonstrates the beneficial effect of the superacid on emerging post-lithium-ion batteries by immobilizing the anion of the salt as well as modifying the SEl composition.

\section{Main Text}

The emergence and fast growth of the electric vehicle market was enabled by the technological maturity of lithium-ion batteries (LIBs) ${ }^{1,2}$. Particularly, a longer driving distance and increased charging speed played a central role in the widespread adoption of LIBs. Nonetheless, the search for new electrode materials has continued as the energy density of current intercalation-based electrode materials is clearly limited in terms of both their gravimetric and volumetric characteristics. The recent considerable attention ${ }^{3,4}$ devoted to lithium metal batteries (LMBs) similarly aimed to increase the energy density as metallic lithium $(\mathrm{Li})$ has a redox potential of $-3.04 \mathrm{~V} v s$. the standard hydrogen electrode and a theoretical specific capacity of $3860 \mathrm{mAh} \mathrm{g}^{-1}$ or $2060 \mathrm{mAh} \mathrm{mL}^{-1}$.

It is well accepted ${ }^{5,6}$ that the uncontrolled growth of Li dendrites imposes a formidable challenge that would need to be addressed to ensure the reversible and sustainable cycling of LMBs. In particular, when the charging current surpasses the so-called Sand's time, the Li-ion concentration at the electrodeelectrolyte interface becomes depleted, thereby allowing dendrites to grow in an accelerated manner 7,8 . This phenomenon indicates the importance of uniform and facile Li ion transport near the Li metal surface, and many reported approaches involving separator coating ${ }^{9-13}$, surface treatments of Li metal ${ }^{14-}$ 18 , and the use of solid electrolytes with high ionic conductivities ${ }^{19-23}$ can be understood in the same context. The solid electrolyte interphase (SEI) layer is also well accepted ${ }^{24,25}$ to play a crucial role in the interfacial stability during repeated Li plating and stripping. A mechanically weak SEI layer is vulnerable 26 to crack formation due to the build-up of stress in the Li deposits underneath. Once the SEl layer breaks down owing to further stress accumulation, the Li deposit could protrude from the layer in the form of dendritic growth. In addition, it is worth keeping in mind that the cell configurations and manufacturing schemes of existing LIBs are preferred when any new approaches are implemented. In this regard, carbonate-based electrolytes are desirable ${ }^{27-29}$ over others because the cathodes to be paired with $\mathrm{Li}$ metal electrodes have been developed on the basis of these electrolytes. However, unfortunately, the 
levels of the lowest unoccupied molecular orbitals (LUMOs) of carbonates are sufficiently low ${ }^{30,31}$ to induce facile reductive decomposition and consequently a weak irregular organic-dominant SEl layer.

$\mathrm{Li}$ ion transport in a liquid electrolyte is affected by multiple parameters including salt dissociation, the degree of solvation, and the viscosity of the solvent, and these parameters are often interrelated to each other. Moreover, Li ion transport and the spatial distribution thereof at the interface are largely influenced by the physicochemical properties of the SEl layer, and the composition of this layer can affect Li nucleation and subsequent growth behavior ${ }^{32,33}$. This rationale led us to pursue an approach by which the dissociation of the Li salt is tuned to obtain a high Li ion transference number, and the dissociated anion can yield an SEl layer with high stability upon reaction with the electrolyte solvents. In this vein, we adopted sulfated zirconia (denoted as $\mathrm{S}-\mathrm{ZrO}_{2}$ ) because $\mathrm{S}-\mathrm{ZrO}_{2}$ can function as a solid acid to promote the dissociation of the Li salt most commonly used in LIBs, namely lithium hexafluorophosphate $\left(\mathrm{LiPF}_{6}\right)$, by strongly binding with the $\mathrm{PF}_{6}{ }^{-}$anion. A solid acid is a class of superacid and exhibits extremely high acidity, even several orders of magnitude higher than that of pure sulfuric acid. The extraordinary acidity of $\mathrm{S}-\mathrm{ZrO}_{2}$ arises ${ }^{34,35}$ from the inductive effect of the sulfate complex with its high electron-withdrawing ability, which enhances the affinity of the superacid for a Lewis base. We applied a coating of S-Z $\mathrm{ZO}_{2}$ superacid nanoparticles to the separator with the aim of distributing the superacid effect over the entire electrode area while simultaneously benchmarking the concept of a ceramic nanoparticle coating to minimize the thermal shrinkage that commercial LIBs are prone to experience at high temperatures. This approach enabled the transference number to reach a value as high as 0.92 as a result of the superacid effect, and this, along with the modified SEl layer involving liberated $\mathrm{PF}_{6}{ }^{-}$anions, resulted in highly reversible and sustainable cyclability of the Li plating-stripping process. In previous studies, solid superacids were implemented ${ }^{36-38}$ in polyethylene oxide (PEO) polymer electrolytes to improve the ionic conductivity or transference number; however, they have not been used in liquid-based cells at all. The present investigation points to the unique advantage offered by superacids: simultaneously high values for both ionic conductivity and transference number, unlike solid-state electrolytes that have a high transference number but are affected by moderate ionic conductivity particularly at the interface, and, needless to mention, poor processability. These beneficial properties are rooted in the physical state of superacid solids; i.e., being solid in nature but functioning in the liquid state.

\section{Synthesis and Coating of Sulfated Zirconia Superacid}

The S- $\mathrm{ZrO}_{2}$ nanoparticles were synthesized via a sol-gel process. Briefly, $1.0 \mathrm{M}$ zirconium $n$ propoxide in anhydrous $n$-propanol was hydrolyzed in a mixture of sulfuric acid and distilled water, followed by condensation at $50^{\circ} \mathrm{C}$ for 1 hour. The compound in the gel state was washed with anhydrous ethanol and centrifuged to accomplish dehydration. Finally, the centrifuged sample was calcined at $600{ }^{\circ} \mathrm{C}$ for 3 hours. Details of the synthetic procedure are provided in the Methods Section. X-ray diffraction (XRD) analysis (Figure 1a) showed that the synthesized compound had a single tetragonal phase belonging to the $\mathrm{P} 4_{2} / \mathrm{nmc}$ space group (ICSD collection code $=66787$ ) without impurities. The FTIR profile of the S-ZrO 2 exhibited peaks at 1213, 1130, 1041, and $995 \mathrm{~cm}^{-1}$ (Figure 1b), which were 
assigned ${ }^{39}$ to the sulfate ion coordinated to $\mathrm{Zr}^{4+}$ in a bidendate configuration. Thermo-gravimetric analysis (TGA) indicated that the sulfate anion content is $10.0 \mathrm{wt} \%$ (Supplementary Figure 1). In addition, the $\mathrm{N}_{2}$ adsorption-desorption isotherm of $\mathrm{S}-\mathrm{ZrO}_{2}$ revealed its surface area to be $104 \mathrm{~m}^{2} \mathrm{~g}^{-1}$, and its primary particle size to be in the range $5-10 \mathrm{~nm}$, as visualized by scanning electron microscopy (SEM) (Figure 1c). After measuring the transference number and assessing the cycling performance with a Li-Li symmetric cell setting by varying the sulfate contents in the range of 2-10 wt\% (Supplementary Figure 2), the sample with sulfate content of $10 \mathrm{wt} \%$ was chosen as the main sample for subsequent experiments.

The polyethylene (PE) separator was coated with the prepared $\mathrm{S}-\mathrm{ZrO}_{2}$ nanoparticles via a simple doctor blading process. The coating was uniformly spread across the entire separator (Figure 1d) to obtain a thickness of 3-4 $\mu \mathrm{m}$ (Figure 1e). As in the current LIB technology, the S- $\mathrm{ZrO}_{2}$ coating serves another purpose namely to ensure the mechanical stability of the membrane against thermal shrinkage. The thermal stability test involved maintaining the separator at $125^{\circ} \mathrm{C}$ for 1 hour, and the $\mathrm{S}-\mathrm{ZrO}_{2}$-coated film was observed to preserve $92.6 \%$ of its original dimension, in contrast with the $78.7 \%$ retention of the bare PE film (Supplementary Figure 3), indicating that the $\mathrm{S}-\mathrm{ZrO}_{2}$ coated separator offers superior mechanical resistance against high temperature.

\section{Symmetric Cell Test and Electrode Analysis}

The effect of the superacid S- $\mathrm{ZrO}_{2}$ on the Li plating and stripping behavior was examined by conducting galvanostatic tests using a Li-Li symmetric cell configuration. For comparison, cells containing the bare PE separator and $\mathrm{ZrO}_{2}$-coated separator were also evaluated in parallel. When scanned at a current density of $3.0 \mathrm{~mA} \mathrm{~cm}^{-2}$ for 1 hour for each Li plating and stripping, the voltage profile of the bare PE cell surpassed $\pm 0.4 \mathrm{~V}$ after 90 cycles (Figure 2), reflecting ${ }^{40}$ uncontrolled SEI growth and subsequent electrolyte depletion. The $\mathrm{ZrO}_{2}$-coated cell extended the cycling slightly and began to surpass $\pm 0.4 \mathrm{~V}$ after 96 cycles. After these points of extremely high overpotentials, these two cells ceased to operate. By contrast, the cycling of the $\mathrm{S}-\mathrm{ZrO}_{2}$-coated cell was sustained much longer such that its overpotential surpassed $\pm 0.4 \mathrm{~V}$ after 821 cycles. The trend among the cells was translated even when the current density was raised to $6.0 \mathrm{~mA} \mathrm{~cm}^{-2}$ for a duration of 0.5 hour for each Li plating and stripping (Supplementary Figure 4), except that the onset point of voltage fluctuations for the $\mathrm{S}-\mathrm{ZrO}_{2}$-- $\mathrm{Coated}$ cell was dragged to around the $559^{\text {th }}$ cycle owing to the higher current density. In the same context, the S$\mathrm{ZrO}_{2}$-coated cell exhibited more sustainable cyclability in an asymmetric cell setting in which copper $(\mathrm{Cu})$ foil was used as one of the electrodes (Supplementary Figure 5).

The effect of the S- $\mathrm{ZrO}_{2}$ superacid coating on the morphology of the Li deposit was investigated using SEM after the $1^{\text {st }}$ and $100^{\text {th }}$ Li plating when galvanostatically scanned at $3.0 \mathrm{~mA} \mathrm{~cm}^{-2}$ for 1 hour for each Li plating and stripping (Figure 3). Even after the $1^{\text {st }}$ charge, the bare PE and $\mathrm{ZrO}_{2}$-coated cells showed extensive growth of Li dendrites with high aspect ratios according to their top-view images 
(Figure 3a and b, first two images), and the thicknesses of the Li plated layers were 63 and $47 \mu \mathrm{m}$, respectively (Figure $3 a$ and $b$, rightmost images), owing to indiscriminate growth of the SEl layer. By contrast, the S- $\mathrm{ZrO}_{2}$-coated cell showed a more compact and distributed Li plated layer with rounded morphology of individual Li deposits (Figure 3c, first two images). The thickness of the Li plated layer was only $39 \mu \mathrm{m}$ (Figure 3c, rightmost image). The difference among the cells became more pronounced after the $100^{\text {th }}$ charge. The growth of sharp Li dendrites continued in the bare PE and $\mathrm{ZrO}_{2}$-coated cells (Figure $3 \mathrm{~d}$ and e, first two images), but most of them could barely be observed because of indiscreet coverage by the SEl layer. The uncontrolled growth of the SEl layer was reflected in the significantly increased thicknesses of the Li plated layers to 250 and $170 \mu \mathrm{m}$, respectively (Figure $3 \mathrm{~d}$ and e, rightmost images). Contrary to this observation, the $\mathrm{S}-\mathrm{ZrO}_{2}$-coated cell preserved the compact morphology of its $\mathrm{Li}$ deposit (Figure 3f, first two images), increasing the thickness of the Li plated layer to only $46 \mu \mathrm{m}$ (Figure $3 \mathrm{f}$, rightmost image). Thus, it can be concluded that the improved cyclability resulting from the $\mathrm{S}^{-} \mathrm{ZrO}_{2}-$ coating observed in Figure 2 is associated with the morphology of the Li deposit, which has a direct impact on the interfacial stability.

\section{Full-Cell and Other Electrochemical Tests}

The reversibility and sustainability of the bare $\mathrm{PE}, \mathrm{ZrO}_{2}$-coated, and $\mathrm{S}-\mathrm{ZrO}_{2}$-coated cells were also evaluated in a full-cell setting paired with $\mathrm{LiNi}_{0.82} \mathrm{Co}_{0.07} \mathrm{Mn}_{0.11} \mathrm{O}_{2}$ cathodes (Figure 4). Notably, Li foil with a thickness of $40 \mu \mathrm{m}$ was used for testing with a relatively practical $\mathrm{n} / \mathrm{p}$ ratio of 3.0. As displayed in Figure $4 \mathrm{a}$, the bare $\mathrm{PE}, \mathrm{ZrO}_{2}$-coated, and $\mathrm{S}-\mathrm{ZrO}_{2}$-coated cells exhibited almost identical charge-discharge profiles in their respective $1^{\text {st }}$ cycles in which an average redox voltage of $3.8 \mathrm{~V}$ and specific capacity of $203.6 \mathrm{mAh} \mathrm{g}^{-1}$ with respect to the cathode weight were observed when scanned at $0.1 \mathrm{C}$ rate $(1 \mathrm{C}=200.0$

$\mathrm{mA} \mathrm{g}_{\text {cathode }}{ }^{-1}$ ), implying that the $\mathrm{S}-\mathrm{ZrO}_{2}$ coating on the separator did not alter the full-cell chemistry.

The cyclability of the S- $\mathrm{ZrO}_{2}$-coated full-cell was conspicuously more robust compared to that of the bare $\mathrm{PE}$ and $\mathrm{ZrO}_{2}$-coated full-cells. Upon cycling at $1 \mathrm{C}\left(3.0 \mathrm{~mA} \mathrm{~cm}{ }^{-2}\right)$, the $\mathrm{S}-\mathrm{ZrO}_{2}$-coated full-cell maintained $83.0 \%$ of its initial capacity after 150 cycles (Figure $4 \mathrm{~b}$ ), whereas the bare PE and $\mathrm{ZrO}_{2}$-coated full-cells preserved $25.2 \%$ and $23.0 \%$ of their initial capacities after the same number of cycles, respectively. The rapid decrease in the capacity of both the bare $\mathrm{PE}$ and $\mathrm{ZrO}_{2}$-coated full-cells was also reflected in their Coulombic efficiency (CE) profiles (Figure 4c). These series of data verify that the superior cyclability obtained with the $\mathrm{S}-\mathrm{ZrO}_{2}$ superacid coating is valid in a practical full-cell setting.

The effect of the separator modifications on the ionic conductivity of Li was assessed by carrying out electrochemical impedance spectroscopy (EIS) analysis (Supplementary Figure 6a). The $x$-intercepts of the EIS profiles reveal that the ionic conductivities of the bare $\mathrm{PE}, \mathrm{ZrO}_{2}$-coated, and $\mathrm{S}-\mathrm{ZrO}_{2}-\mathrm{Coated}_{\text {cells }}$ are $0.64,0.51$, and $0.49 \mathrm{mS} \mathrm{cm}^{-1}$, respectively (Figure $5 \mathrm{a}$ ), indicating that the application of $\mathrm{ZrO}_{2}$ and S$\mathrm{ZrO}_{2}$ coatings did not change the ionic conductivity markedly. Moreover, the three cells were subjected to 
$5 \mathrm{mV}$ bias for 12 hours to monitor the impedance change until they reached the steady state (Supplementary Figure 6b). These measurements were used to retrieve the transference numbers (Figure $5 b)$ based on the equation 41,42 :

$$
t_{L i^{+}}=\frac{I_{S s} \times\left(\Delta V-I_{0} \times R_{0}\right)}{I_{0} \times\left(\Delta V-I_{s s} \times R_{s s}\right)}
$$

where , $I_{S S} I_{0}, R_{S S}, R_{0}$, and $\Delta V$ represent the Li-ion transference number, steady-state current, initial current, steady-state resistance, initial resistance, and applied voltage $(5 \mathrm{mV})$, respectively. Notably, the transference number of the $\mathrm{S}-\mathrm{ZrO}_{2}$-coated cell increased dramatically to 0.92 from 0.36 for the bare $\mathrm{PE}$ cell and 0.38 for the $\mathrm{ZrO}_{2}$-coated cell, implying that the superacidity of $\mathrm{S}-\mathrm{ZrO}_{2}$ enhances the migration of $\mathrm{Li}^{+}$exclusively from the $\mathrm{PF}_{6}{ }^{-}$anion. Notably, this transference number is higher than those of any liquidbased Li cells reported to date $\mathrm{e}^{43,44}$, including the implementation ${ }^{45}$ of a metal-organic framework (MOF) layer $(=\sim 0.7)$ in which anionic sub-nanometer channels screen anions in the electrolyte.

\section{Origin of High $\mathrm{Li}^{+}$Transference Number}

Raman and ${ }^{31} \mathrm{P}$ solid NMR analyses were carried out to determine the origin of the high $\mathrm{Li}^{+}$ transference number of the $\mathrm{S}-\mathrm{ZrO}_{2}$-coated cell. The Raman analysis (Figure 6a) unveils the dissociative nature of the $\mathrm{LiPF}_{6}$ salt and its interaction with the solvent. This analysis entailed examining the carbonate electrolyte $\left(1 \mathrm{M} \mathrm{LiPF}_{6}\right.$ in ethylene carbonate $(\mathrm{EC})$ and diethyl carbonate $(\mathrm{DEC}), 3: 7=v . v$ with 10 vol\% fluoroethylene carbonate (FEC)) after soaking the bare PE, $\mathrm{ZrO}_{2}$-coated, and S-ZrO separators in the electrolyte for 24 hours. The Raman spectra of the three samples exhibited similar peak intensities at $728 \mathrm{~cm}^{-1}$, related ${ }^{46}$ to $\mathrm{Li}^{+}$-EC interaction, indicating that the solvation environment of the $\mathrm{Li}^{+}$ion with EC was not perturbed significantly by the addition of the $\mathrm{S}-\mathrm{ZrO}_{2}$ superacid. However, the peak intensity of the free $\mathrm{PF}_{6}{ }^{-}$anion at $741 \mathrm{~cm}^{-1}$ relative to that of the free $\mathrm{EC}$ peak at $716 \mathrm{~cm}^{-1}$ decreased for the S-Z $\mathrm{Zr}_{2}$-coated separator compared with the bare PE and $\mathrm{ZrO}_{2}$-coated separators (intensity ratio: 0.82 vs. 0.97 vs. 0.94). This observation reveals the Lewis acid-base interaction between the $\mathrm{S}-\mathrm{ZrO}_{2}$ superacid and $\mathrm{PF}_{6}{ }^{-}$, providing the reason for the increased $\mathrm{Li}^{+}$ion transference number in the case of the $\mathrm{S}^{-} \mathrm{ZrO}_{2}{ }^{-}$ coated separator. In a similar context, the ${ }^{31} \mathrm{P}$ solid NMR spectrum of the $\mathrm{S}-\mathrm{ZrO}_{2}$ soaked in the electrolyte exhibited a band in the range $-10 \sim-30$ ppm corresponding to the $\mathrm{PO}_{y} \mathrm{~F}_{6-y}{ }^{\delta-}$ anion ${ }^{47}$, which was barely observed for the $\mathrm{ZrO}_{2}$ counterpart and was not observed at all for bare $\mathrm{LiPF}_{6}$. The appearance of this band is attributed to the reaction of the $\mathrm{PF}_{6}{ }^{-}$anion bound to $\mathrm{S}-\mathrm{ZrO}_{2}$ with a trace amount of water. This role of the $\mathrm{S}-\mathrm{ZrO}_{2}$ superacid is indeed analogous to the way in which $\mathrm{S}-\mathrm{ZrO}_{2}$ offers superacidity: the Lewis acid sites in the $\mathrm{S}-\mathrm{ZrO}_{2}$ superacid attract electron-donating groups (Supplementary Figure 7). 


\section{Effect of Sulfated Zirconia on the SEI Properties}

The modified potentiostatic intermittent titration (PITT) technique was employed to examine the electrolyte decomposition behavior at different potentials below the $\mathrm{Li} / \mathrm{Li}^{+}$standard potential (Figure $6 \mathrm{c}$ ). This analysis was conducted by decreasing the potential in decrements of $2 \mathrm{mV}$ and maintaining the potential at each decremental level for 1 hour to record the electron consumption. In both cells, electrolyte decomposition was observed in the potential range of $-8 \sim-30 \mathrm{mV} v \mathrm{~L}$. $\mathrm{Li} / \mathrm{Li}^{+}$before $\mathrm{Li}$ deposition was detected below $-32 \mathrm{mV}$ with far greater electron consumption. Notably, the amount of electron consumption used for electrolyte decomposition was substantially larger for the $\mathrm{S}-\mathrm{ZrO}_{2}$-coated cell compared with the bare PE cell, revealing that SEI formation was more prominent in the S- $\mathrm{ZrO}_{2}$-coated cell at higher potentials. Computational calculations were conducted to elucidate the augmented SEI formation in the $\mathrm{S}-\mathrm{ZrO}_{2}$-coated cell (Figure $6 \mathrm{~d}$ ). We estimated the energy levels of the lowest unoccupied molecular orbital (LUMO) of the $\mathrm{PF}_{6}{ }^{-}$anion, its derivatives upon reaction with water (i.e., $\mathrm{PO}_{x} \mathrm{~F}_{y}$ ), and the carbonate solvents included in the electrolyte. According to the results, the first oxidized form of $\mathrm{PF}_{6}{ }^{-}$, $\mathrm{POF}_{3}$, has a lower LUMO energy level compared to those of the carbonate solvents. Considering that the LUMO energy level generally represents a reduction priority, our results suggested that the $\mathrm{POF}_{3}$ formed at the surface of $\mathrm{S}-\mathrm{ZrO}_{2}$ serves as the origin of the prominent electrolyte decomposition of the $\mathrm{S}-\mathrm{ZrO}_{2}$ coated case.

Furthermore, the onset potential for $\mathrm{Li}$ deposition was approximately $14 \mathrm{mV}$ higher for the $\mathrm{S}-\mathrm{ZrO}_{2}-$ coated cell compared with the bare PE cell ( -32 vs. $-46 \mathrm{mV}$ ) (Figure 6c), inferring ${ }^{48,49}$ that the modified SEl layer lowers the activation energy for Li deposition. Additionally, the SEI layer of the S- $\mathrm{ZrO}_{2}-\mathrm{coated}$ cell proved to be more robust than that of the bare PE cell (Supplementary Figure 8). When the symmetric cells were left standing for a different number of days after one cycle of Li plating and stripping, the increase in the semicircle of the EIS profile was much more prominent for the bare PE cell (Supplementary Figure 8a) compared with that of the $\mathrm{S}-\mathrm{ZrO}_{2}$-coated cell (Supplementary Figure 8b), pointing to inferior SEl stability in the bare PE case.

The effect of the S-ZrO ${ }_{2}$ superacid on the SEl composition was studied by X-ray photoelectron spectroscopy (XPS). The XPS spectra of the $\mathrm{S}-\mathrm{ZrO}_{2}$ superacid before and after its immersion in the electrolyte for 24 hours were compared for the $\mathrm{Zr} 3 d, 01 s, \mathrm{~S} 2 p, \mathrm{P} 2 p$, and F $1 s$ branches (Supplementary Figure 9). After immersion, new peaks appeared at higher binding energies of 187.6, 533.5, and $170.8 \mathrm{eV}$

in the $\mathrm{Zr} 3 d, 01 s$, and $\mathrm{S} 2 \mathrm{p}$ branches, respectively, which could likely be attributed to $\mathrm{Zr}-\mathrm{PO}_{y} \mathrm{~F}_{z}, \mathrm{P}-\mathrm{O}-\mathrm{F}^{50}$, and $\mathrm{S}-\mathrm{O}$ in the sulfate. However, further investigation is needed as the peaks at 187.6 and $170.8 \mathrm{eV}$ were unidentified in the literature. At the same time, a combined analysis of the profiles in the $\mathrm{P} 2 p$ and $\mathrm{F} 1 \mathrm{~s}$ branches indicates the formation of $\mathrm{PO}_{y} \mathrm{~F}_{z}{ }_{z}$, which is once again commensurate with the aforementioned observation related to the reaction of a trace amount of water with $\mathrm{PF}_{6}{ }^{-}$bound to the $\mathrm{S}-\mathrm{ZrO}_{2}$ superacid. When XPS analysis preceded by 300 seconds of etching was performed for Li metal electrodes after the $1^{\text {st }}$ Li plating (Supplementary Figure 10), the peak of the F $1 \mathrm{~s}$ branch appeared at $687.2 \mathrm{eV}$ and the peaks 
of the $\mathrm{P} 2 p$ branch were observed at 136.2 and $134.1 \mathrm{eV}$. This revealed an SEl composition containing $\mathrm{Li}_{x} \mathrm{PO}_{y} \mathrm{~F}_{Z}$, which is consistent with that of the immersed $\mathrm{S}-\mathrm{ZrO}_{2}$ superacid described above, along with the fact that the interior of the SEl layer is rich in inorganic components. It should be noted that the complete removal of trace water from most carbonate electrolytes is impossible. In our experiment, the formation of $\mathrm{PO}_{y} \mathrm{~F}_{z}{ }^{-}$was preserved even after the electrolyte was stored over molecular sieves to reduce the amount of trace water, implying that the observed effect of the $\mathrm{S}-\mathrm{ZrO}_{2}$ superacid on the SEl composition is consistent regardless of the amount of trace water present in typical carbonate electrolytes. In addition, the XRD profiles of S-ZrO ${ }_{2}$ remained unchanged (Supplementary Figure 11), thus supporting the catalytic role of the $\mathrm{S}-\mathrm{ZrO}_{2}$ superacid in increasing the transference number of the $\mathrm{Li}$ ion as well as inducing the $\mathrm{PO}_{y} \mathrm{~F}_{z}$-rich SEl layer.

\section{Conclusion}

Interfacial stability is of key importance for the reliable operation of Li metal anodes and is greatly affected by the Li ion transference number and SEI characteristics. In spite of the widely accepted consensus in this regard, achieving the desired properties related to these parameters without sacrificing the volumetric energy density is no trivial matter; for instance, the integration of additional components that increase the Li ion transference number is mostly foreign to the current LIB technology and therefore demerits the use of a Li metal anode after comprehensive evaluation.

In this sense, the approach introduced in the present study, namely the incorporation of the $\mathrm{S}-\mathrm{ZrO}_{2}$ superacid, is effective yet realistic because the application of a coating of ceramic material to the separator is being adopted in most of the cells that are currently commercially available. Moreover, the effect of the given approach is substantial as the $\mathrm{S}-\mathrm{ZrO}_{2}$ superacid enhances binding with the anion of the Li salt, which increases the mobility of the Li ion apart from inducing a more stable SEl layer. While this view of the superacid-anion interaction was supported by Raman and ${ }^{31} \mathrm{P} N \mathrm{NR}$ analyses, its outcome was electrochemically validated in both symmetric- and full-cell configurations. Taking a broad perspective, the solid-state nature of the superacid warrants its easy integration into a cell and we thus foresee the universal applicability of the positive effects of the superacid to a wide range of rechargeable batteries beyond LMBs.

\section{Methods}

Synthesis of sulfated $\mathrm{ZrO}_{2}$ superacid and $\mathrm{ZrO}_{2}$ particles. $70 \mathrm{wt} \%$ zirconium $n$-propoxide (Sigma-Aldrich) in $20 \mathrm{~mL}$ of propanol (Sigma-Aldrich) was first mixed with $62.2 \mathrm{~mL}$ of anhydrous $n$-propanol $(99.7 \%$ purity, Sigma-Aldrich). To this solution, $1.10 \mathrm{~mL}$ of sulfuric acid (99.999\% purity, Sigma-Aldrich) and $14.81 \mathrm{~mL}$ of distilled water were added sequentially for $10 \mathrm{~min}$ at $50{ }^{\circ} \mathrm{C}$ until the vortex disappeared. The solution was then aged at the same temperature for another hour. Next, $100 \mathrm{~mL}$ of ethanol $(\geq 99.5 \%$, Sigma-Aldrich) was added and the solution was centrifuged at $6000 \mathrm{rpm}$ for $10 \mathrm{~min}$ to switch the solvent from water to alcohol to minimize particle growth during drying and calcination. This washing via 
centrifugation was repeated three times. The produced powder was dried at $80^{\circ} \mathrm{C}$ for 12 hours to remove residual alcohol, followed by calcination at $600{ }^{\circ} \mathrm{C}$ for 3 hours to produce the designated crystal structure. For S- $\mathrm{ZrO}_{2}$ with 2 and $6 \mathrm{wt} \%$ sulfate, the same procedure was adopted except that 0.28 and $0.55 \mathrm{~mL}$ of sulfuric acid was added, respectively. The bare $\mathrm{ZrO}_{2}$ particles were synthesized based on the same procedure as $\mathrm{S}-\mathrm{ZrO}_{2}$ particles except that sulfuric acid was not added.

Coating of $\mathrm{S}-\mathrm{ZrO}_{2}$ and $\mathrm{ZrO}_{2}$ particles on the separator. The PE separator ( $16 \mu \mathrm{m}$ thick, Toray) was coated with the synthesized $\mathrm{S}-\mathrm{ZrO}_{2}$ and $\mathrm{ZrO}_{2}$ particles by using the doctor blading technique with $33 \mathrm{wt} \% \mathrm{~S}-\mathrm{ZrO}{ }_{2}$ or $\mathrm{ZrO}_{2}$ solution. The areal loading was $1.0 \mathrm{mg} \mathrm{cm}^{-2}$ in both cases. For the thermal shrinkage test, separators with dimensions of $4.0 \times 4.0 \mathrm{~cm}^{2}$ were left in an oven at $125^{\circ} \mathrm{C}$ for 1 hour and the dimensional changes were measured.

Electrochemical analysis. The symmetric cell tests were conducted by sandwiching various polyethylene separators between two sheets of Li foil (200 $\mu \mathrm{m}$ thick, Honjo Metal Co., Ltd.) and galvanostatically cycled at 3.0 or $6.0 \mathrm{~mA} \mathrm{~cm}^{-2}$. Each charge or discharge was continued for 1 hour in the case of $3.0 \mathrm{~mA}$ $\mathrm{cm}^{-2}$ and 0.5 hour in the case of $6.0 \mathrm{~mA} \mathrm{~cm}^{-2}$. The electrolyte was $1 \mathrm{M} \mathrm{LiPF}_{6}$ in EC/DEC ( $\left.v / v=3 / 7\right)$ with 10 vol\% FEC. The cells that were used for the asymmetric cell tests were prepared by using the same procedure except that one side of the electrodes was replaced by Cu foil. For the full-cell tests, $\mathrm{LiNi}_{0.82} \mathrm{Co}_{0.07} \mathrm{Mn}_{0.11} \mathrm{O}_{2}$ cathodes were fabricated by first preparing a slurry consisting of the active material, Super P, and poly(vinylidene difluoride) (PVDF) in a weight ratio of 96:2:2 in N-methyl-2pyrrolidone (NMP). The slurry was cast onto Al foil via the doctor blade method and dried at $120^{\circ} \mathrm{C}$ for 12 hours. The areal loading of the active material was $15.5 \mathrm{mg} \mathrm{cm}^{-2}$. The Li metal foil on the anode side was $40 \mu \mathrm{m}$ thick. The electrolyte was the same as that used in the symmetric cells. The full-cells were precycled at $0.1 \mathrm{C}$ and cycled at $1 \mathrm{C}\left(1 \mathrm{C}=200 \mathrm{~mA} \mathrm{~g}_{\mathrm{NCM}^{-1}}\right)^{-1}$ in subsequent cycles. The amount of the electrolyte was $80 \mu \mathrm{L}$ for each coin cell. Both symmetric and full-cells were prepared in the form of 2032 coin cells by assembling the anode, cathode, and separator in a dry room. The ionic conductivity of each separator was assessed by performing EIS analysis, which was carried out in the frequency range of $10^{-2}-10^{6} \mathrm{~Hz}$ with an amplitude of $10 \mathrm{mV}$. The ionic conductivity was retrieved from the $x$-axis intercept of each profile. The transference number was obtained by monitoring the change in the current when subjected to an applied voltage based on the following relation 41,42 :

$$
t_{L i^{+}}=\frac{I_{s s} \times\left(\Delta V-I_{0} \times R_{0}\right)}{I_{0} \times\left(\Delta V-I_{s s} \times R_{s s}\right)}
$$

where $I_{S S}$ is steady state current, $I_{0}$ is initial current, $R_{S S}$ is steady state resistance, $R_{0}$ is initial resistance, and $\Delta V$ is voltage applied ( $5 \mathrm{mV}$ in the current study). Modified PITT analysis was conducted by applying constant voltage for one hour at every $2 \mathrm{mV}$ while the current was monitored. The measured potential ranged from 0 to $-50 \mathrm{mV} v s$. $\mathrm{Li} / \mathrm{Li}^{+}$. To test the stability of the SEl layer, EIS analysis was performed after leaving the symmetric cells for a different number of days after undergoing one cycle of Li plating and 
stripping (C-rate $=0.1 \mathrm{C}$, capacity of each plating and stripping $=3 \mathrm{mAh}$ ). These measurements were recorded in the frequency range of $10^{-2}-10^{6} \mathrm{~Hz}$ with an amplitude of $10 \mathrm{mV}$.

Characterization of S-ZrO ${ }_{2}$ and $\mathrm{ZrO}_{2}$ particles. XRD (Empyrean, PANanalytic) and FTIR (VERTEX 70, Bruker) analyses were carried out to characterize the crystal structures and chemical bonds of the S-ZrO and $\mathrm{ZrO}_{2}$ particles, respectively. TGA (TG/DTA 6300, PerkinElmer) was used to evaluate the sulfate content in $\mathrm{S}-\mathrm{ZrO}_{2}$. SEM analysis (JSM-7000F, JEOL) was performed to visualize the morphology of the Li metal deposits on the surface. Raman analysis with a laser excitation wavelength of $532 \mathrm{~nm}$ (Senterra Grating 400, Bruker) was carried out for the electrolytes in which the different separators were soaked for 24 hours to monitor the ion-to-solvent interaction. ${ }^{31} \mathrm{P}$ solid NMR analysis (ASCEND, Bruker) was conducted for the $\mathrm{S}-\mathrm{ZrO}_{2}$ and $\mathrm{ZrO}_{2}$ particles soaked in the electrolyte for 24 hours. The conditions for ${ }^{31} \mathrm{P}$ solid NMR analysis were such that the spinning frequency, dwell time, pre-scan delay, recycle delay, excitation pulse length, and excitation pulse power were $11 \mathrm{kHz}, 6.3 \mathrm{msec}, 6.3 \mathrm{msec}, 0.5 \mathrm{sec}, 5.0 \mathrm{msec}$, and $50 \mathrm{~W}$, respectively. XPS (Scientific K-ALPHA, Thermo Fisher) was used to elucidate the SEI components.

DFT calculation. Geometrical optimizations and energy calculations were performed without symmetry restriction using the B3LYP hybrid density functional implemented in the GAUSSIAN 09 software package ${ }^{51}$. The $6-311+G(d, p)$ basis sets were adopted for all the atoms. Frequency calculations at the same basis sets were performed to determine the nature of a stationary point as a true local minimum.

\section{Declarations}

\section{Data availability}

The data that support the plots within this paper and other findings of this study are available from the corresponding authors upon reasonable request.

\section{Acknowledgements}

We acknowledge the support by the L\&F Co.'s World Class 300 Project of the Korea Institute of Advancement of Technology (KIAT) funded by the Ministry of Trade, Industry, and Energy \& Ministry of SMEs and Startups (No. S2483103) and the National Research Foundation of Korea (NRF) grant funded by the Korea government (MEST) (NRF-2018M1A2A2063353, NRF-2018M1A2A2063340 and NRF2018R1A2A1A19023146).

\section{Author contributions}

S.-G.W., J.-S.Y., and J.W.C. designed the research. S.-G.W., E.-K.H., H.-K.K., H.L., J.-N.L, G.J., J.L., and S.K. performed the experimental work. D.-J.Y. performed the DFT calculations. S.-G.W., J.-S.Y., and J.W.C. wrote the manuscript. All authors discussed the results and commented on the manuscript. 
Additional information

Supplementary information is available online. Reprints and permissions information is available online at www.nature.com/reprints. Correspondence and requests for materials should be addressed to J.-S.Y. and J.W.C.

\section{Competing interests}

The authors declare no competing financial interests.

\section{References}

1 Dunn, B., Kamath, H. \& Tarascon, J.-M. Electrical energy storage for the grid: a battery of choices. Science 334, 928 (2011).

2 Choi, J. W. \& Aurbach, D. Promise and reality of post-lithium-ion batteries with high energy densities. Nat. Rev. Mater. 1, 16013 (2016).

3 Albertus, P., Babinec, S., Litzelman, S. \& Newman, A. Status and challenges in enabling the lithium metal electrode for high-energy and low-cost rechargeable batteries. Nat. Energy 3, 16-21 (2018).

4 Guo, Y., Li, H. \& Zhai, T. Reviving lithium-metal anodes for next-generation high-energy batteries. Adv. Mater. 29, 1700007 (2017).

5 Liang, X. et al. A facile surface chemistry route to a stabilized lithium metal anode. Nat. Energy 2, 17119 (2017).

6 Fang, C. et al. Quantifying inactive lithium in lithium metal batteries. Nature 572, 511-515 (2019).

7 Bai, P., Li, J., Brushett, F. R. \& Bazant, M. Z. Transition of lithium growth mechanisms in liquid electrolytes. Energy Environ. Sci. 9, 3221-3229 (2016).

8 Yoo, D.-J., Kim, K. J. \& Choi, J. W. The synergistic effect of cation and anion of an ionic liquid additive for lithium metal anodes. Adv. Energy Mater. 8, 1702744 (2018).

9 Tu, Z. et al. Designing artificial solid-electrolyte interphases for single-ion and high-efficiency transport in batteries. Joule 1, 394-406 (2017).

10 Liu, K. et al. Extending the life of lithium-based rechargeable batteries by reaction of lithium dendrites with a novel silica nanoparticle sandwiched separator. Adv. Mater. 29, 1603987 (2017). 
11 Wu, J. et al. Ultralight layer-by-layer self-assembled MoS2-polymer modified separator for simultaneously trapping polysulfides and suppressing lithium dendrites. Adv. Energy Mater. 8, 1802430 (2018).

$12 \mathrm{He}$, Y. et al. Simultaneously inhibiting lithium dendrites growth and polysulfides shuttle by a flexible MOF-based membrane in Li-S batteries. Adv. Energy Mater. 8, 1802130 (2018).

13 Zhao, C.-Z. et al. An ion redistributor for dendrite-free lithium metal anodes. Sci. Adv. 4, eaat3446 (2018).

14 Choi, S. H. et al. Marginal magnesium doping for high-performance lithium metal batteries. Adv. Energy Mater. 9, 1902278 (2019).

15 Pang, Q., Liang, X., Kochetkov, I. R., Hartmann, P. \& Nazar, L. F. Stabilizing lithium plating by a biphasic surface layer formed in situ. Angew. Chem. Int. Ed. 57, 9795-9798 (2018).

$16 \mathrm{Gu}, \mathrm{Y}$. et al. Designable ultra-smooth ultra-thin solid-electrolyte interphases of three alkali metal anodes. Nat. Commun. 9, 1339 (2018).

17 Tu, Z. et al. Fast ion transport at solid-solid interfaces in hybrid battery anodes. Nat. Energy 3, 310-316 (2018).

18 Kim, M. S. et al. Langmuir-Blodgett artificial solid-electrolyte interphases for practical lithium metal batteries. Nat. Energy 3, 889-898 (2018).

19 Liang, J.-Y. et al. Engineering janus interfaces of ceramic electrolyte via distinct functional polymers for stable high-voltage Li-metal batteries. J. Am. Chem. Soc. 141, 9165-9169 (2019).

20 Cheng, Q. et al. Stabilizing solid electrolyte-anode interface in Li-metal batteries by boron nitridebased nanocomposite coating. Joule 3, 1510-1522 (2019).

$21 \mathrm{Xu}, \mathrm{H}$. et al. Li3N-modified garnet electrolyte for all-solid-state lithium metal batteries operated at $40{ }^{\circ} \mathrm{C}$. Nano Lett. 18, 7414-7418 (2018).

22 Fan, X. et al. Fluorinated solid electrolyte interphase enables highly reversible solid-state Li metal battery. Sci. Adv. 4, eaau9245 (2018).

23 Wang, P. et al. Electro-chemo-mechanical issues at the interfaces in solid-state lithium metal batteries. Adv. Funct. Mater. 29, 1900950 (2019).

24 Liu, J. et al. Pathways for practical high-energy long-cycling lithium metal batteries. Nat. Energy 4, 180-186 (2019).

25 Fan, X. et al. Non-flammable electrolyte enables Li-metal batteries with aggressive cathode chemistries. Nat. Nanotechnol. 13, 715-722 (2018). 
$26 \mathrm{Xu}, \mathrm{W}$. et al. Lithium metal anodes for rechargeable batteries. Energy Environ. Sci. 7, 513-537 (2014).

27 Chen, S. et al. High-voltage lithium-metal batteries enabled by localized high-concentration electrolytes. Adv. Mater. 30, 1706102 (2018).

$28 \mathrm{Li}, \mathrm{T}$., Zhang, X.-Q., Shi, P. \& Zhang, Q. Fluorinated solid-electrolyte interphase in high-voltage lithium metal batteries. Joule 3, 2647-2661 (2019).

29 Yamada, Y., Wang, J., Ko, S., Watanabe, E. \& Yamada, A. Advances and issues in developing saltconcentrated battery electrolytes. Nat. Energy 4, 269-280 (2019).

30 Borodin, O. et al. (Invited) challenges with quantum chemistry-based screening of electrochemical stability of lithium battery electrolytes. ECS Trans. 69, 113-123 (2015).

31 Wang, A., Kadam, S., Li, H., Shi, S. \& Qi, Y. Review on modeling of the anode solid electrolyte interphase (SEI) for lithium-ion batteries. NPJ Comput. Mater. 4, 15 (2018).

32 Pang, Q., Liang, X., Shyamsunder, A. \& Nazar, L. F. An in vivo formed solid electrolyte surface layer enables stable plating of Li metal. Joule 1, 871-886 (2017).

33 Yoo, D.-J. et al. Tuning the electron density of aromatic solvent for stable solid-electrolyteinterphase layer in carbonate-based lithium metal batteries. Adv. Energy Mater. 8, 1802365 (2018).

34 Jin, T., Yamaguchi, T. \& Tanabe, K. Mechanism of acidity generation on sulfur-promoted metal oxides. J. Phys. Chem. 90, 4794-4796 (1986).

35 Bolis, V., Magnacca, G., Cerrato, G. \& Morterra, C. Microcalorimetric characterization of structural and chemical heterogeneity of superacid $\mathrm{SO}_{4} / \mathrm{ZrO}_{2}$ systems. Langmuir $13,888-894$ (1997).

36 Xi, J. \& Tang, X. Nanocomposite polymer electrolyte based on Poly(ethylene oxide) and solid super acid for lithium polymer battery. Chem. Phys. Lett. 393, 271-276 (2004).

37 Sannier, L., Zalewska, A., Wieczorek, W., Marczewski, M. \& Marczewska, H. Impact of "Super Acid" like filler on the properties of a PEGDME/LiClO 4 system. Electrochim. Acta 52, 5685-5689 (2007).

38 Derrien, G., Hassoun, J., Sacchetti, S. \& Panero, S. Nanocomposite PEO-based polymer electrolyte using a highly porous, super acid zirconia filler. Solid State Ion. 180, 1267-1271 (2009).

39 Sohn, J. R. et al. Highly active catalyst of $\mathrm{NiO}-\mathrm{ZrO}_{2}$ modified with $\mathrm{H}_{2} \mathrm{SO}_{4}$ for ethylene dimerization. Appl. Catal., A 128, 127-141 (1995).

40 Chen, K.-H. et al. Dead lithium: mass transport effects on voltage, capacity, and failure of lithium metal anodes. J. Mater. Chem. A 5, 11671-11681 (2017). 
41 Evans, J., Vincent, C. A. \& Bruce, P. G. Electrochemical measurement of transference numbers in polymer electrolytes. Polymer 28, 2324-2328 (1987).

42 Bruce, P. G., Evans, J. \& Vincent, C. A. Conductivity and transference number measurements on polymer electrolytes. Solid State Ion. 28-30, 918-922 (1988).

43 Wang, Z. et al. Self-assembly of $\mathrm{PEI} / \mathrm{SiO}_{2}$ on polyethylene separators for $\mathrm{Li}$-lon batteries with enhanced rate capability. ACS Appl. Mater. Interfaces 7, 3314-3322 (2015).

$44 \mathrm{Chi}, \mathrm{M}$. et al. Excellent rate capability and cycle life of Li metal batteries with $\mathrm{ZrO}_{2} / \mathrm{POSS}$ multilayer-assembled PE separators. Nano Energy 28, 1-11 (2016).

45 Bai, S. et al. High-power Li-metal anode enabled by metal-organic framework modified electrolyte. Joule 2, 2117-2132 (2018).

46 Mukai, K., Inoue, T., Kato, Y. \& Shirai, S. Superior low-temperature power and cycle performances of $\mathrm{Na-ion}$ battery over Li-ion battery. ACS Omega 2, 864-872 (2017).

47 Han, J.-G., Kim, K., Lee, Y. \& Choi, N.-S. Scavenging materials to stabilize LiPF 6 -containing carbonate-based electrolytes for Li-lon batteries. Adv. Mater. 31, 1804822 (2019).

48 Kim, K.-E. et al. A combination of lithium difluorophosphate and vinylene carbonate as reducible additives to improve cycling performance of graphite electrodes at high rates. Electrochem. Commun. 61, 121-124 (2015).

49 Yang, B., Zhang, H., Yu, L., Fan, W. \& Huang, D. Lithium difluorophosphate as an additive to improve the low temperature performance of $\mathrm{LiNi}_{0.5} \mathrm{Co}_{0.2} \mathrm{Mn}_{0.3} \mathrm{O}_{2} /$ graphite cells. Electrochim. Acta 221, 107-114 (2016).

50 Baggetto, L., Dudney, N. J. \& Veith, G. M. Surface chemistry of metal oxide coated lithium manganese nickel oxide thin film cathodes studied by XPS. Electrochim. Acta 90, 135-147 (2013).

51 Kohn, W. \& Sham, L. J. Self-consistent equations including exchange and correlation effects. Phys. Rev. 140, A1133-A1138 (1965).

\section{Figures}



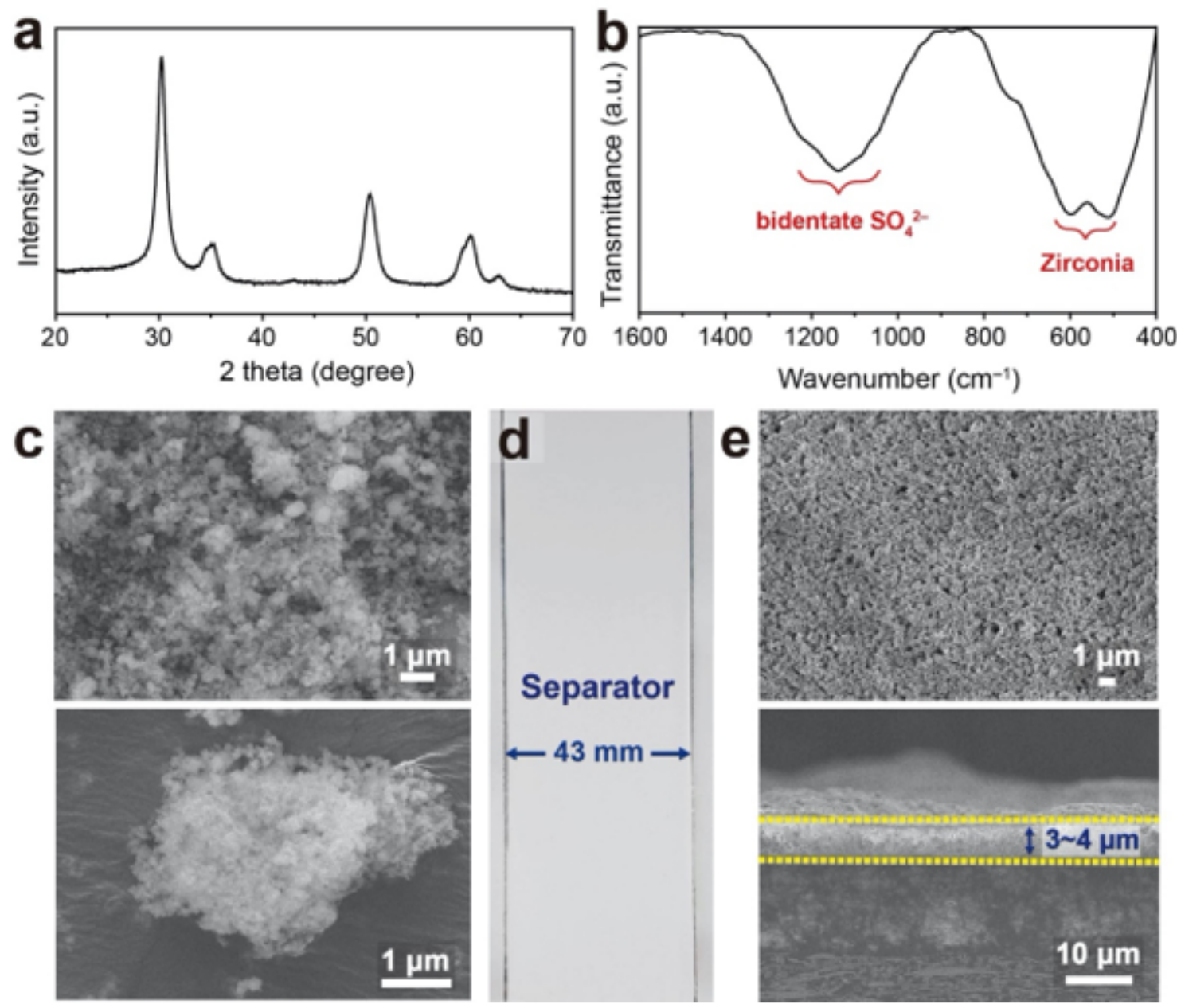

\section{Figure 1}

Synthesis and coating of S-ZrO2 particles. a-b, (a) XRD and (b) FTIR profiles of S-ZrO2 particles. c, SEM images of S-ZrO2 particles. d, Digital photograph of PE separator coated with S-ZrO2 particles. e, Topview and cross-sectional SEM images of the coating of S-ZrO2 particles on the PE separator.

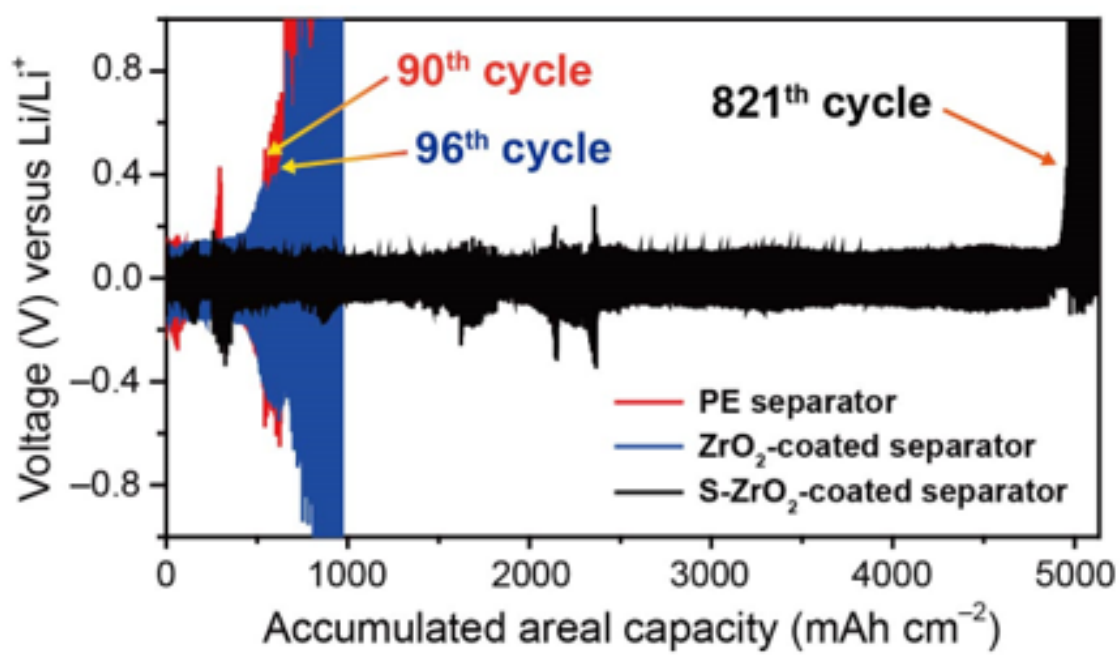


Figure 2

Symmetric cell testing. Voltage profiles of the bare PE, ZrO2-coated, and S-ZrO2-coated symmetric cells when galvanostatically scanned at $3.0 \mathrm{~mA} \mathrm{~cm}-2$ for 1 hour for each Li plating and stripping.

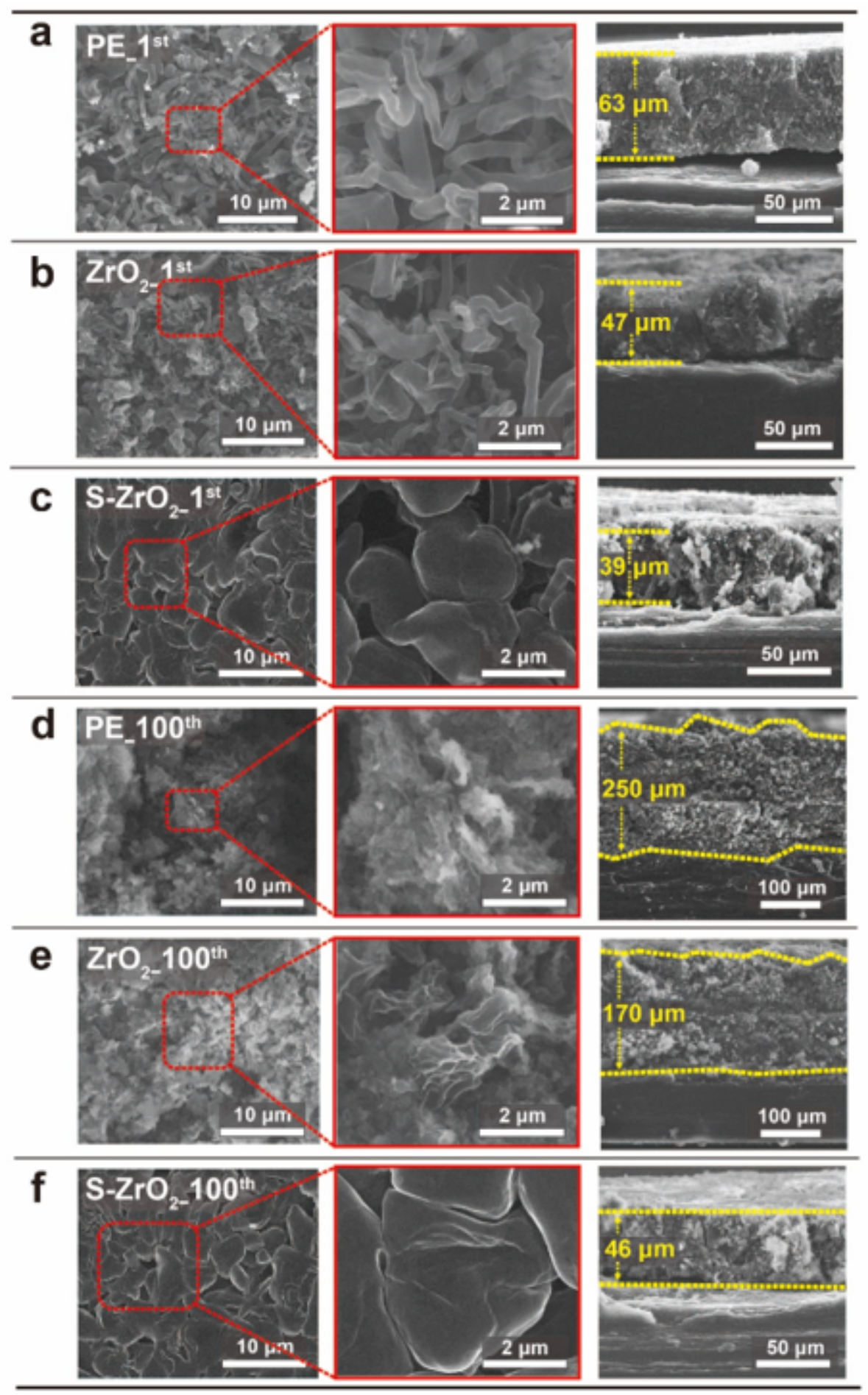

\section{Figure 3}

Morphology of lithium deposit at 1 st and 100th cycle. a-c, Top-view and cross-sectional SEM images after the 1st Li plating at $3.0 \mathrm{~mA} \mathrm{~cm}-2$ for 1 hour: Li electrodes of (a) PE_reference, (b) ZrO2-separator, 
and (c) S-ZrO2-separator cells. $d$-f, Top-view and cross-sectional SEM images after the 100th Li plating at $3.0 \mathrm{~mA} \mathrm{~cm}-2$ for 1 hour: Li electrodes of (d) PE_reference, (e) ZrO2-separator, and (f) S-ZrO2-separator cells.
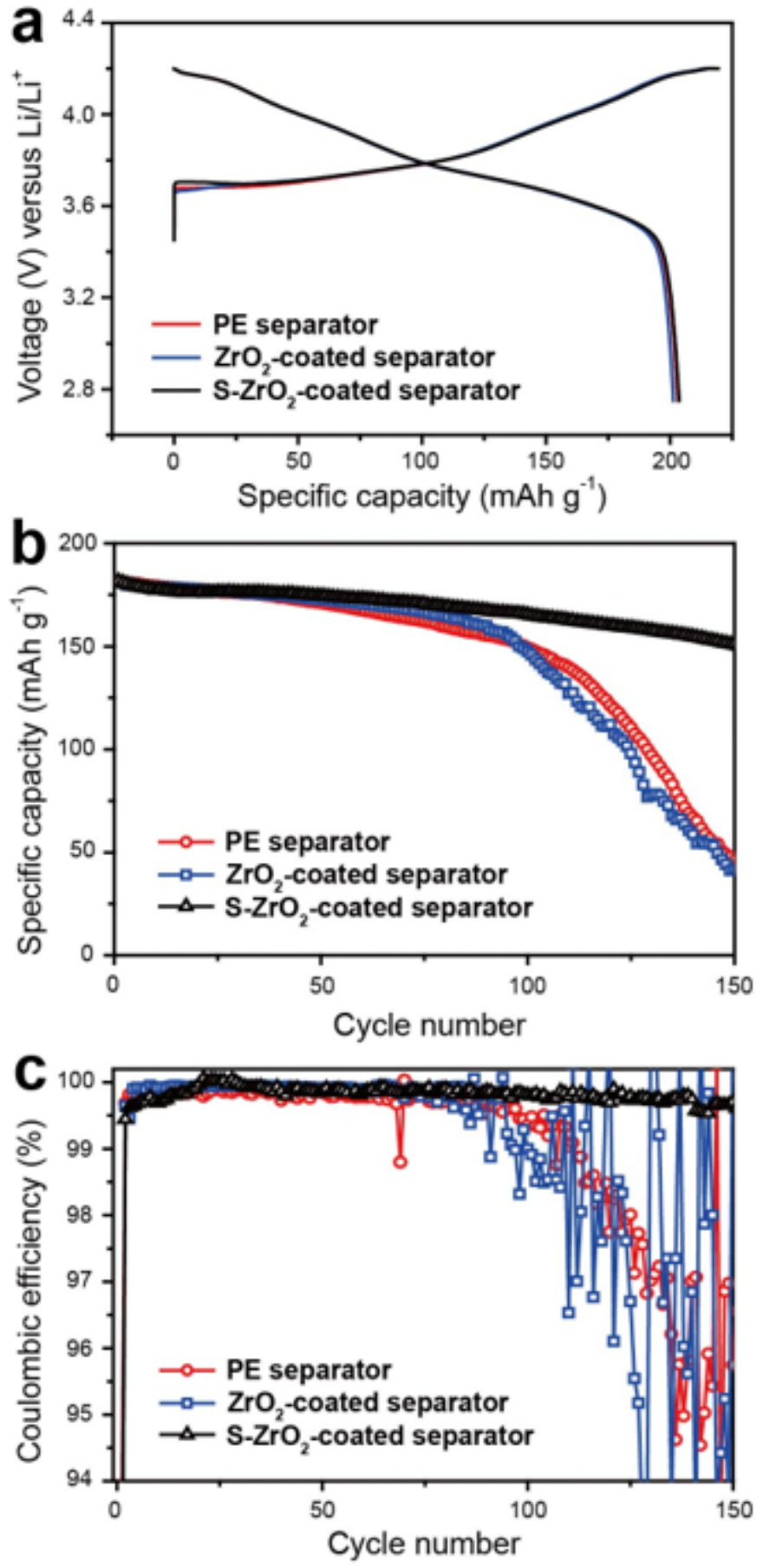

\section{Figure 4}

Full-cell testing when paired with the LiNi0.82Co0.07Mn0.1102 cathode. a-c, (a) Initial voltage profiles, (b) capacity retentions, and (c) Coulombic efficiencies of the bare PE, ZrO2-coated, and S-ZrO2-coated 
full-cells when paired with LiNi0.82Co0.07Mn0.1102 cathodes. The C-rates in (a) and (b-c) are 0.1C and $1 \mathrm{C}$, respectively $(1 \mathrm{C}=200.0 \mathrm{~mA}$ gcathode -1$)$.
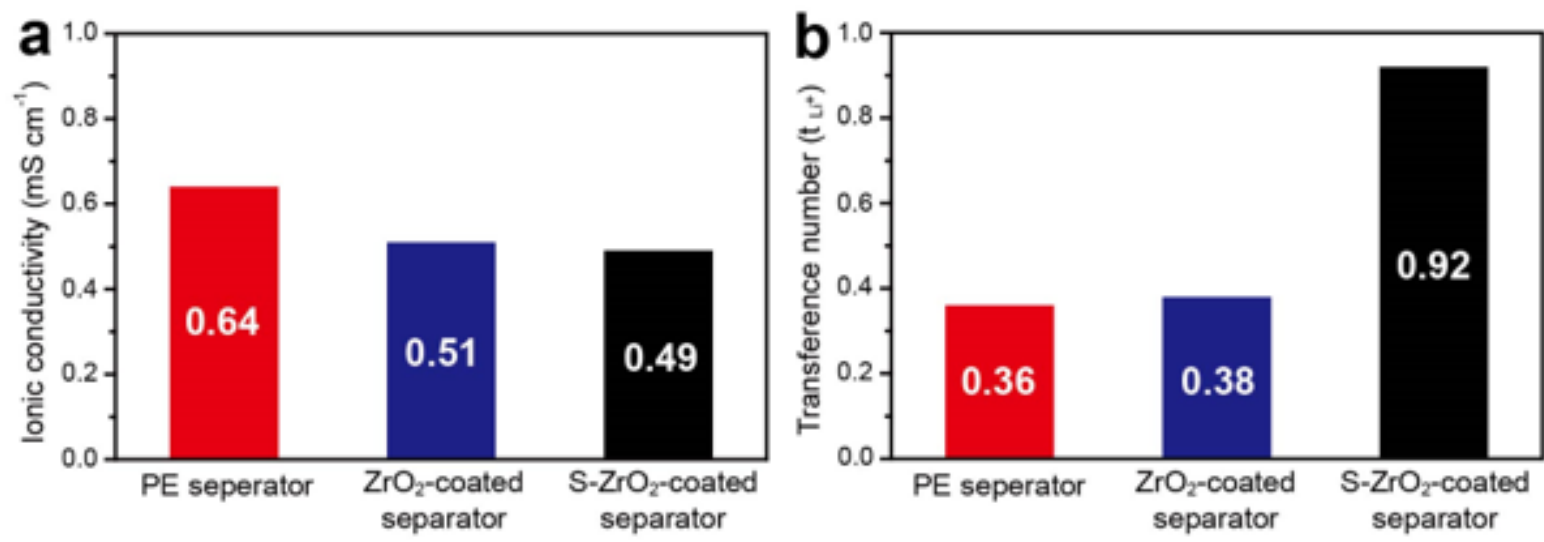

\section{Figure 5}

$\mathrm{Li}$ ion transport behavior with different separators. a, lonic conductivities of the bare PE, ZrO2-coated PE, and S-ZrO2-coated PE separators. b, Li ion transference numbers of the same three separators.
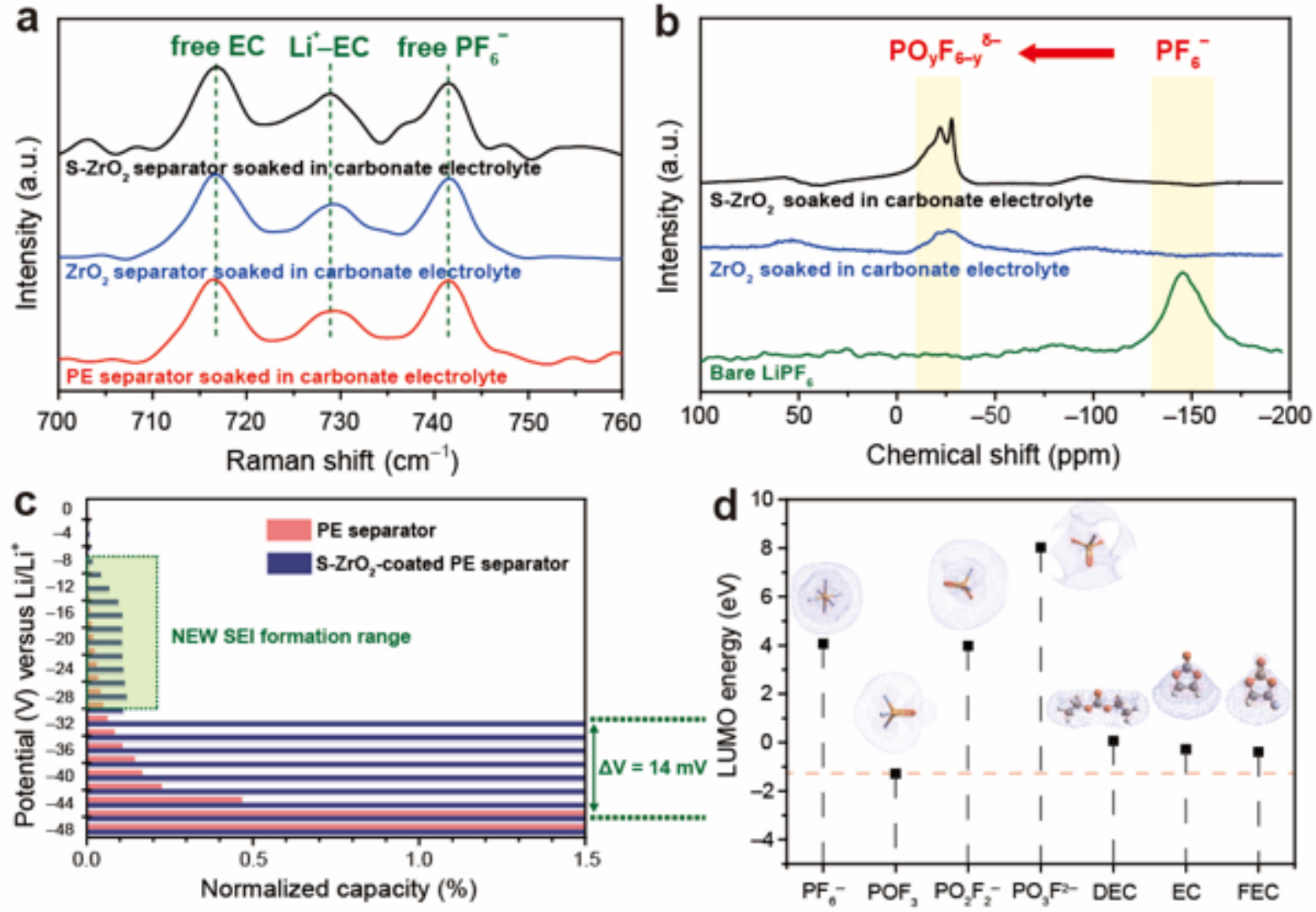

Figure 6 
Effect of S-ZrO2 superacid on ion dissociation and SEl composition. a, Raman spectra of the electrolyte after soaking the bare PE, ZrO2-coated PE, and S-ZrO2-coated PE separators in the electrolyte for 24 hours. b, 31P solid NMR spectra of the S-ZrO2 and ZrO2 after soaking in the carbonate electrolyte along with the profile of bare LiPF6. c, PITT profiles of the bare PE and S-ZrO2-coated cells for an applied potential below that of $\mathrm{Li} / \mathrm{Li}+$. d, LUMO energy levels of PF6-, its derivatives, and the carbonate solvents.

\section{Supplementary Files}

This is a list of supplementary files associated with this preprint. Click to download.

- Slrevisedfinal.pdf 